Cereal Research Communications DOI: 10.1556/CRC.2013.0059

\title{
Micronutrient Contents and Nutritional Values of Commercial Wheat Flours and Flours of Field-grown Wheat Varieties - A Survey in Hungary
}

\author{
F. SZIRA**, I. MONOSTORI**, G. GALIBA, M. RAKSZEGI and A.F. BÁlinT* \\ Agricultural Institute, Centre for Agricultural Research, Hungarian Academy of Sciences, Brunszvik u. 2, \\ H-2462 Martonvásár, Hungary \\ (Received 18 April 2013; accepted 10 June 2013; \\ Communicated by A. Aniol)
}

\begin{abstract}
Wheat-based food has great importance in human nutrition: in European countries they provide $20-30 \%$ of the daily calorie intake, and additionally, the wholemeal and healthy food becomes even more popular. Mineral content in grains is dependent on genetic and environmental factors (varieties, soil type, geographical location of the growing area, etc.), therefore, it is complicated to estimate how many percentage of the daily micronutrient requirements can be covered by wheat-based products. In this study, copper $(\mathrm{Cu})$, iron $(\mathrm{Fe})$, manganese $(\mathrm{Mn})$, molybdenum (Mo), selenium (Se) and zinc ( $\mathrm{Zn}$ ) contents of 13 commercial wheat flour products, and the white flour and wholemeal of 24 winter type bread wheat varieties were studied to estimate the nutritional value of these products. All investigated samples were produced in Hungary. Significant variation was revealed in the case of all mineral elements in the different brands of wheat flours. Generally, the white flour enriched with germ showed higher mineral contents than the average values of normal white flours. Furthermore, the wholemeal has higher $\mathrm{Cu}, \mathrm{Fe}, \mathrm{Mn}$ and $\mathrm{Zn}$, but not higher Se contents than the white flours. Mo content was also higher in some brands of white flour than in wholemeal.

The investigated winter wheat varieties showed significant differences in the case of Fe, $\mathrm{Mn}, \mathrm{Se}$ and $\mathrm{Zn}$ contents, but none of the varieties showed outstandingly high micronutrient content. The milling process - as it was expected - reduces the concentrations of four elements (Fe 33\%; Mn 88\%; Zn 71\%; Cu 44\%); however, the Se and Mo concentrations were not affected significantly. Using the average micronutrient content in the wholemeal of varieties, the daily $\mathrm{Mn}$ and $\mathrm{Fe}$ requirement can be covered by the consumption of about $250 \mathrm{~g}$ wholemeal. Additionally, the daily Mo requirement could be met by the daily consumption of 140-190 g of commercial white or wholemeal flour.
\end{abstract}

Keywords: micronutrients, wholemeal, flour, winter wheat, human nutrition, nutritional value, biofortification

\footnotetext{
* Corresponding author; E-mail: afbalint@yahoo.co.uk

** These authors contributed equally to this work.
} 


\section{Introduction}

In European countries, the cereals and primarily the wheat provide about $20-30 \%$ of the daily calorie intake, while it is about $50 \%$ in Central Asia on average (Chakmak 2008). Unfortunately, the wheat grains often contain very low amounts of micronutrients. There are four main reasons of this: (i) The grains of Poales have inherently low concentrations of minerals compared to other cultivated plants: especially $\mathrm{Ca}$ and $\mathrm{Mg}$ concentrations are low (Broadley et al. 2004). (ii) The cereals can also be grown on micronutrient deficient soils, which could be resulted in lower grain nutrient concentrations. (iii) The increased grain yield and thousand-kernel weights of modern varieties as well as the changes in the ratio of bran to endosperm can also result in a relative lower micronutrient concentration in wheat grain. Oury et al. (2006) found negative correlation between grain yield and $\mathrm{Mg}$ and $\mathrm{Zn}$ concentration. Additionally, negative correlation was found between the date of the variety release and the $\mathrm{Zn}$ and Fe concentration (Zhao et al. 2009; Monasterio and Graham 2000). (iv) Milling is also a critical process affecting the concentration of minerals of wheat-based products. However, the concentration losses as a consequence of the milling can be significantly different among elements (Cubadda et al. 2009).

In recent years the wholemeal, organic products and healthy food become even more popular. It is also generally accepted that wholemeal is healthier and contains more nutrients than white flour. Although, data regarding the micronutrient content of wholemeal and white flour products available on the European or Hungarian market is incomplete. The micronutrient content of flours produced from wheat growing on the same type of soil is determined fundamentally by the varieties. Therefore, the evaluation of the wheat varieties regarding to their micronutrient content is also necessary.

Artificial fortification of food with minerals is a traditional strategy, although this method is too expensive. Biofortification - micronutrient fertilization or breeding lines with higher grain nutrient content - is a cost-effective and more sustainable approach to enhance micronutrient content of cereal-based foods (Mayer et al. 2008). The first step in the production of healthier wheat-based food should be the evaluation of grains of modern varieties, wholemeal and flour products in respect of micronutrients.

Based on this, the main objective of this study was to investigate the copper $(\mathrm{Cu})$, iron (Fe), manganese (Mn), molybdenum (Mo), selenium (Se) and zinc ( $\mathrm{Zn}$ ) contents in wheat wholemeal and flour samples distributed under different brand names in Hungary and in grains in some Hungarian wheat varieties. The effect of milling on micronutrient content, the variance between the varieties and the possible daily micronutrient intake from wheat in Hungary are also discussed.

\section{Materials and Methods}

Thirteen currently available, different types and brands of wheat flours (10 white flours: 7 BL55, 1 BL55 enriched with wheat germ and 2 BFF5; 2 semolina and 1 wholemeal) were studied for their mineral nutrient composition. The 13 samples represented 8 brands: Gyermelyi, Sikér, CBA, Príma, Szatmári Malom Kft., No-Name "Búza finomliszt", 
Pannon Búza-finomliszt, and Vitamill. BL55 and BFF55 are both white wheat flours named by Hungarian milling products standard (Codus Alimentarius Hungaricus 2007) but BL-55 has smaller particle size than BFF-55. Samples were bought in 07.09.2011 at the local shop of a national supermarket chain in Martonvásár, Hungary.

Additionally, the micronutrient contents of wholemeals in 24 winter type bread wheat varieties (Bánkúti 1201, Mv Apród, Mv Béres, Mv Bodri, Mv Csárdás, Mv Karizma, Mv Kikelet, Mv Ködmön, Mv Kolo, Mv Kolompos, Mv Lucilla, Mv Magdaléna, Mv Marsall, Mv Mazurka, Mv Menüett, Mv Petrence, Mv Suba, Mv Süveges, Mv Tallér, Mv Toborzó, Mv Toldi, Mv Verbunkos, Mv Walzer) were also examined and compared.

The varieties were sown in the experimental field at the Agricultural Institute of HAS-CAR (Martonvásár, Hungary) in the autumn of 2009 and 2010. Each variety was sown in two replicate plots of $2 \mathrm{~m}$ long and 6 rows, spaced at a distance of $20 \mathrm{~cm}$ in both years. Fertilizers and pest control were applied similarly as described by Ward et al. (2008). Wheat grain was harvested at maturity in 2010 and 2011. Grain samples from the two replicate plots per year were combined. Mineral content of the grain samples harvested in 2010 and 2011 were determined. Additionally, white flour was produced from the grain samples harvested in 2010 and the mineral content of the flour was also analyzed. The milling was carried out using Chopin (CD1) laboratory mill.

The grain and flour samples were analyzed for Cu-, Fe-, Mn-, Mo-, Se- and Zn-content by using an Atomic Absorption Spectrometer (AAS, SOLAAR M6 Series AA, Thermo Scientific, Waltham, USA) with a similar method described by Erba et al. (2011). The micronutrients evaluated in $\mathrm{m} \mathrm{kg}^{-1}$ were investigated by using a flame burner, while the elements evaluated in $\mu \mathrm{g} \mathrm{kg}^{-1}$ with a graphite furnace method. Each measurement was carried out on three replicates.

Statistical analysis (descriptive statistic, ANOVA) was performed by using the software SPSS ver. 17.0 for Windows (SPSS 2008).

\section{Results}

\section{Variation in mineral contents of commercial wheat flour in Hungary}

Seven different brands of Hungarian white flour BL55 were analyzed in respect of their mineral composition (Table 1). Interestingly, significant differences were found in the case of all mineral elements. Despite the significant effects, it means only $1-2 \mathrm{mg} \mathrm{kg}^{-1}$ differences in $\mathrm{Cu}, \mathrm{Mn}$ and $\mathrm{Zn}$ contents. Twofold differences were found among the white flour in the Fe and Mo concentration, while the maximum Se content measured in this selection was fivefold higher than the minimum.

The white flour enriched with germ showed higher mineral contents than the average values of normal white flour, and it has higher Mo concentration than the wholemeal. It was expected that wholemeal has higher micronutrient content than white flours. It was true for $\mathrm{Cu}, \mathrm{Fe} \mathrm{Mn}$ and $\mathrm{Zn}$ contents but interestingly, lower Se content was found in wholemeal than in most of white flours and semolina. Besides, Mo content was also higher not only in white flour enriched with germ but in some additional BL55 white 
Table 1. Average micronutrient concentration of commercially available different wheat flour (A) and analysis of variance (B)

\begin{tabular}{|c|c|c|c|c|c|c|}
\hline \multicolumn{7}{|l|}{$\mathrm{A}$} \\
\hline & $\begin{array}{c}\mathrm{Cu} \\
\left(\mathrm{mg} \mathrm{kg}^{-1}\right)\end{array}$ & $\begin{array}{c}\mathrm{Fe} \\
\left(\mathrm{mg} \mathrm{kg}^{-1}\right)\end{array}$ & $\begin{array}{c}\mathrm{Mn} \\
\left(\mathrm{mg} \mathrm{kg}^{-1}\right)\end{array}$ & $\begin{array}{c}\text { Mo } \\
\left(\mu \mathrm{g} \mathrm{kg}^{-1}\right)\end{array}$ & $\begin{array}{c}\mathrm{Se} \\
\left(\mu \mathrm{g} \mathrm{kg}^{-1}\right)\end{array}$ & $\begin{array}{c}\mathrm{Zn} \\
\left(\mathrm{mg} \mathrm{kg}^{-1}\right)\end{array}$ \\
\hline White flour BL55 (7) & $2.16 * * *$ & $8.48 * * *$ & $6.53 * * *$ & $245.7 * * *$ & $54.5 * * *$ & $8.11 * * *$ \\
\hline Min. & 1.81 & 6.36 & 5.69 & 183.0 & 25.0 & 7.65 \\
\hline Max. & 2.41 & 12.46 & 7.18 & 377.5 & 133.5 & 8.79 \\
\hline \multicolumn{7}{|l|}{ White flour BL55 with } \\
\hline germ (embryo) (1) & 2.98 & 9.30 & 9.57 & 362.0 & 60.0 & 10.25 \\
\hline White flour BFF55 (2) & 1.54 & 5.48 & 2.86 & 158.0 & 101.1 & 4.60 \\
\hline Grits (Semolina) (2) & 2.88 & 8.30 & 7.55 & 296.7 & 46.4 & 8.96 \\
\hline Wholemeal (1) & 3.88 & 25.65 & 27.65 & 330.5 & 33.4 & 25.15 \\
\hline \multicolumn{7}{|l|}{$\mathrm{B}$} \\
\hline & \multicolumn{6}{|c|}{ F-value } \\
\hline & $\mathrm{Cu}$ & $\mathrm{Fe}$ & $\mathrm{Mn}$ & Mo & $\mathrm{Se}$ & $\mathrm{Zn}$ \\
\hline \multirow[t]{2}{*}{ Flour type } & 127.16 & 519.77 & 817.19 & 40.45 & 22.59 & 639.83 \\
\hline & $* * *$ & $* * *$ & $* * *$ & $* * *$ & $* * *$ & \\
\hline
\end{tabular}

Number of the investigated samples is presented in brackets.

*** Significant at the $\mathrm{P} \leq 0.001$ probability levels

Min.: minimum; Max.: maximum

flours. ANOVA was made in different types of wheat flours and significant differences were found in all the cases of micronutrients (Table 1B). F-value was the highest for Fe, $\mathrm{Mn}$ and $\mathrm{Zn}$ content indicating the greatest variability between flour types. Based on the post-hoc test (data not shown) this clear effect would be the consequence that the wholemeal has more than twofold $\mathrm{Fe}, \mathrm{Mn}$ and $\mathrm{Zn}$ contents, than other flour types.

\section{Variation in mineral contents of wheat varieties}

Interestingly, no significant difference was found in $\mathrm{Cu}$ content of the grain of the varieties (Table 2). In the case of Fe, significant variation was caused by the year effect, while the Mn content of the varieties was significantly affected by the genotype and year effect, too. Mv Toldi showed the highest $\left(49.1 \mathrm{mg} \mathrm{kg}^{-1}\right) \mathrm{Mn}$ content in both years, but in the case of many genotypes it was dependent upon the year: Mv Bodri has $29.1 \mathrm{mg} \mathrm{kg}^{-1} \mathrm{Mn}$ content in 2010 while $42.3 \mathrm{mg} \mathrm{kg}^{-1}$ in 2011. Variation in Se content was mainly due to the effect of the year while the genotype effect was significant also for $\mathrm{Zn}$. The wholemeal of the varieties Mv Bodri $\left(14.75 \pm 0.21 \mathrm{mg} \mathrm{kg}^{-1}\right)$ has consequently low $\mathrm{Zn}$ content, while Bánkúti-1201 (25.4 $\left.0 \pm 0.57 \mathrm{mg} \mathrm{kg}^{-1}\right)$ and Mv Kolompos $\left(27.75 \pm 2.62 \mathrm{mg} \mathrm{kg}^{-1}\right)$ showed the highest level of $\mathrm{Zn}$ content in both years. Unfortunately, the determination of Mo content failed in some samples from 2010 therefore the analysis of variance was not calculated.

\section{Effect of milling on micronutrient concentration}

White flour and wholemeal of 24 varieties were compared to analyze the effect of milling process on the micronutrient content. As we expected, after milling, a significant decrease 
Table 2. Mean values and range of grain nutrient concentration of 24 wheat varieties grown under field condition in 2010 and 2011 (A) and the analysis of variance (B)

\begin{tabular}{|c|c|c|c|c|c|c|c|}
\hline \multicolumn{8}{|l|}{ A } \\
\hline & & $\begin{array}{c}\mathrm{Cu} \\
\left(\mathrm{mg} \mathrm{kg}^{-1}\right)\end{array}$ & $\begin{array}{c}\mathrm{Fe} \\
\left(\mathrm{mg} \mathrm{kg}^{-1}\right)\end{array}$ & $\begin{array}{c}\mathrm{Mn} \\
\left(\mathrm{m} \mathrm{kg}^{-1}\right)\end{array}$ & $\begin{array}{c}\text { Mo } \\
\left(\mu \mathrm{gg}^{-1}\right)\end{array}$ & $\begin{array}{c}\mathrm{Se} \\
\left(\mu \mathrm{g} \mathrm{kg}^{-1}\right)\end{array}$ & $\begin{array}{c}\mathrm{Zn} \\
\left(\mathrm{mg} \mathrm{kg}^{-1}\right)\end{array}$ \\
\hline \multirow[t]{3}{*}{2010} & av. & 2.77 & 35.47 & 37.69 & - & 45.7 & 20.53 \\
\hline & $\min$. & 1.83 & 29.40 & 29.10 & - & 26.9 & 14.60 \\
\hline & $\max$ & 4.37 & 44.80 & 48.80 & - & 81.6 & 27.70 \\
\hline \multirow[t]{3}{*}{2011} & av. & 2.89 & 30.57 & 41.20 & 94.0 & 77.6 & 18.90 \\
\hline & $\min$. & 2.27 & 24.40 & 34.30 & 45.4 & 47.8 & 14.00 \\
\hline & $\max$ & 4.29 & 38.20 & 49.40 & 187.0 & 129.0 & 29.60 \\
\hline \multicolumn{8}{|l|}{ B } \\
\hline & & \multicolumn{6}{|c|}{ F-value } \\
\hline & & $\mathrm{Cu}$ & $\mathrm{Fe}$ & $\mathrm{Mn}$ & Mo & $\mathrm{Se}$ & $\mathrm{Zn}$ \\
\hline \multirow{2}{*}{\multicolumn{2}{|c|}{ Year }} & 1.11 & 15.35 & 14.35 & - & 12.39 & 1.34 \\
\hline & & NS & $* * *$ & $* *$ & & $* *$ & - \\
\hline \multirow{2}{*}{\multicolumn{2}{|c|}{ Genotype }} & 1.34 & 1.27 & 2.98 & - & 0.95 & 2.71 \\
\hline & & NS & NS & $*$ & & NS & $*$ \\
\hline
\end{tabular}

$*, * *, * * *$ Significant at the $\mathrm{P} \leq 0.05,0.01$ and 0.001 probability levels, respectively

NS: non-significant; av.: average; min.: minimum; max.: maximum

in the concentration of most of the elements was observed, except of Mo and Se. Mo showed a slight decrease in the concentration - less than $10 \%$-, which was not significant (Table 3). Additionally, slight, non-significant increase of Se content was found in the white flour compared to wholemeal. The $\mathrm{Cu}, \mathrm{Fe}, \mathrm{Mn}$ and $\mathrm{Zn}$ content in the wholemeal of varieties was significantly higher than those measured in white flour of the varieties. A group of three elements showed a major concentration decrease as the consequence of milling, i.e. $\mathrm{Fe}(73 \%), \mathrm{Mn}(88 \%)$ and $\mathrm{Zn}(71 \%)$. Copper showed a concentration decrease of $44 \%$ in this study.

Table 3. Comparison of the micronutrient contents of white flour and wholemeal of 24 wheat varieties harvested in 2010

\begin{tabular}{llcccrrr}
\hline & & $\begin{array}{c}\mathrm{Cu} \\
\left(\mathrm{mg} \mathrm{kg}^{-1}\right)\end{array}$ & $\begin{array}{c}\mathrm{Fe} \\
\left(\mathrm{mg} \mathrm{kg}^{-1}\right)\end{array}$ & $\begin{array}{c}\mathrm{Mn} \\
\left(\mathrm{mg} \mathrm{kg}^{-1}\right)\end{array}$ & $\begin{array}{c}\mathrm{Mo} \\
\left(\mu \mathrm{g} \mathrm{kg}^{-1}\right)\end{array}$ & $\begin{array}{c}\mathrm{Se} \\
\left(\mu \mathrm{g} \mathrm{kg}^{-1}\right)\end{array}$ & $\begin{array}{c}\mathrm{Zn} \\
\left(\mathrm{mg} \mathrm{kg}^{-1}\right)\end{array}$ \\
\hline White flour & av. & $1.56^{* * *}$ & $9.26^{* * *}$ & $4.51^{* * *}$ & 99.4 & 57.4 & $5.78^{* * *}$ \\
& min. & 0.79 & 7.19 & 3.03 & 73.4 & 34.1 & 4.43 \\
& max. & 2.53 & 22.30 & 6.32 & 170.0 & 132.0 & 8.92 \\
\hline Wholemeal & av. & 2.77 & 35.47 & 37.69 & 108.5 & 45.7 & 20.53 \\
& min. & 1.83 & 29.40 & 29.10 & 63.2 & 26.9 & 14.60 \\
& max. & 4.37 & 44.80 & 48.80 & 163.0 & 81.6 & 27.70 \\
\hline
\end{tabular}

*** Significant at the $\mathrm{P} \leq 0.001$ probability levels av.: average; min.: minimum; max.: maximum 


\section{Discussion}

Fe is an essential micronutrient both for plants and humans. Graham et al. (2007) found that the average $\mathrm{Fe}$ concentration in wheat grain is $35 \mathrm{mg} \mathrm{kg}^{-1}$. In this study similar concentration was found in the varieties, and the highest $\mathrm{Fe}$ content was found in the $\mathrm{Mv}$

Béres $\left(44.8 \mathrm{mg} \mathrm{kg}^{-1}\right)$. The Fe content of the commercial wholemeal was threefold higher than in white flour and the data on varieties showed that $73 \%$ of the Fe content is lost during milling. The recommended daily Fe intake is $8 \mathrm{mg}$ per day (Dietary Reference Intake 2004) and is based on the average Fe content of varieties, which can be reached by the consumption of at least $220 \mathrm{~g}$ wholemeal.

Based on the two-year experiment of varieties, no significant genotype but positive year effect was found for $\mathrm{Fe}$ (Table 2). Oury et al. (2006) also found non-significant genotype effect for $\mathrm{Fe}$ concentration in wheat grain, examining 61 genotypes at four locations. It was suggested that the variability of $\mathrm{Fe}$ in wheat grain mainly depends on genotype by environment interaction, therefore the selection and breeding for this trait is more difficult.

The average $\mathrm{Zn}$ concentration in wholegrain of wheat in various countries is between 20 to $35 \mathrm{mg} \mathrm{kg}^{-1}$ (Cakmak et al. 2004). The average $\mathrm{Zn}$ content of the varieties and the commercial flour samples is slightly lower and ranged between $19-25 \mathrm{mg} \mathrm{kg}^{-1}$.

Most of the $\mathrm{Zn}$ is located in the aleuron layer and embryo, whereas the endosperm has very low $\mathrm{Zn}$ concentration. The $\mathrm{Zn}$ concentration is about $150 \mathrm{mg} \mathrm{kg}^{-1}$ in the embryo and aleuron layer, and only $15 \mathrm{mg} \mathrm{kg}^{-1}$ in endosperm (Ozturk et al. 2006). During the milling process the Zn rich parts of the wheat grain - the embryo and aleuron layer - are removed. The data on varieties also showed that only $29 \%$ of the total grain $\mathrm{Zn}$ content remained in the white flour. It was also found that different types of white flours and semolina have significantly lower $\mathrm{Zn}$ content than wholemeal. It was also expectable that white flour enriched with germ has higher $\mathrm{Zn}$ content than white flour.

Cultivated wheat contains very low concentration of $\mathrm{Zn}$, compared to wild wheat and it has a narrow genetic variation (Cakmak 2008). In this study, significant genotype effect was found among 24 Hungarian wheat genotypes; however, the highest $\mathrm{Zn}$ content (29.60 $\mathrm{mg} \mathrm{kg}^{-1}$ ) was still too low to meet daily human requirements from wheat. It is recommended that the $\mathrm{Zn}$ concentration in wholegrain needs to be increased up to $44 \mathrm{mg} \mathrm{kg}^{-1}$, assuming $250 \mathrm{~g}$ per day intake of wholegrain flour to reach the recommended daily $\mathrm{Zn}$ intake (11 mg per day, Dietary Reference Intake 2004). Oury et al. (2006) found high genotype by environment interaction effect and considering the narrow genetic variation for $\mathrm{Zn}$. Therefore, the application of $\mathrm{Zn}$ containing fertilizers - agronomic biofortification under field condition could be the best way to increase grain $\mathrm{Zn}$ content.

Selenium is mostly in protein-bound form in wheat grain, therefore it is more evenly distributed in the kernel, and a higher proportion is stored in the endosperm, compared to other minerals (Lyons et al. 2005b). Thus, the milling process of wheat grains reduces not, or only slightly the Se concentration in the end-product. It was shown that the amount of total grain, Se retained in the flour was 71.2 and $66.4 \%$ for the low and high Se-containing wheat grains, respectively (Garvin et al. 2011). Interestingly, in this study the Se content 
in commercial wholemeal was lower than in the white flour samples. Additionally, in varieties no significant differences in Se content of white flour and wholemeal was detected.

Recent analysis of selenium content in flour samples from Argentina reveals that the contribution of wheat flour to the daily Se intake is about $14 \%$, and the average Se content of representative flour samples ranged between 22-42 $\mu \mathrm{g} \mathrm{kg}^{-1}$ (Sigrist et al. 2012). In another study 13-99 $\mu \mathrm{g} \mathrm{kg}^{-1}$ Se content was reported (Murphy and Cashman 2001). Our study reveals a slightly higher variation in Se content of wheat flour $\left(54-133 \mu \mathrm{g} \mathrm{kg}^{-1}\right)$. Assuming $250 \mathrm{~g}$ per day intake of wheat flour, $10-26 \%$ of the recommended Se intake (55 $\mu \mathrm{g}$, Dietary Reference Intake 2004) can be covered in Hungary.

Se is not an essential element for plants, and its concentration in grains correlates with plant-available selenium in soils (Spadoni et al. 2007). The soil pH, the microbial activity, the content of organic materials and the soil texture are all important parameters that affect the concentration of available Se in soil (Stroud et al. 2010). Lyons et al. (2005a) concluded that genotypic differences may exist between varieties, but they are likely too small compared to the variation in available Se concentration in soils. This is in agreement with the data present in Table 2, that variability in Se content depends on year - environment effect. It was also found that differences in Se content of 26 bread wheat lines were not significant in the multiple environment trial (Zhao et al. 2009). It is also expected that the differences in Se content of different type of commercial meal samples are the consequences of the different cultivation area.

$\mathrm{Cu}, \mathrm{Mn}$ and Mo are mainly present in the aleuron layer of the wheat grains, so the wholemeal is an important source of these mineral and trace elements.

$\mathrm{Cu}$ showed a concentration decrease of $44 \%$ upon milling in this study (Table 3 ). This is similar to the results obtained in a previous study that about $45 \%$ of $\mathrm{Cu}$ is in the endosperm of common wheat kernel (O'Dell 1972). Bálint et al. (2001) found 6.5-11.3 mg $\mathrm{kg}^{-1} \mathrm{Cu}$ concentration in different Triticum L. species. In this study lower, $2.77 \mathrm{mg} \mathrm{kg}^{-1}$ average $\mathrm{Cu}$ content was found in wheat varieties (T. aestivum ssp. aestivum). The recommended daily intake of $\mathrm{Cu}$ is $0.9 \mathrm{mg}$ (Dietary Reference Intake 2004) and this requirement could be met by the daily consumption of at least $320 \mathrm{~g}$ of wholemeal. There was no significant difference in $\mathrm{Cu}$ concentration of varieties. This suggests that the genetic variation in $\mathrm{Cu}$ content may be small in modern varieties, and another source of new genetic material should be found to increase the $\mathrm{Cu}$ content in the seeds of modern cultivars.

Significantly different $\mathrm{Mn}$ contents were observed in the grains of the different wheat varieties: it was ranged from 29.1 to $49.4 \mathrm{mg} \mathrm{kg}^{-1}$. The variance was strongly affected by the year, but the genotype effect was also significant in this study. The range was similar to that reported for 31 durum wheat genotypes tested in Turkey (Oktem and Oktem 2009), but in $T$. dicoccoides larger variation (13-87 mg kg-1) was found (Gomez-Becerra et al. 2010). The analysis of genetic variation and environmental stability of grain mineral concentration in wild emmer wheat was also shown: genotype is an important source of variation $(20 \%)$ for $\mathrm{Mn}$, but the environment explains higher, $58.4 \%$ of the total variance (Gomez-Becerra et al. 2010).

Interestingly, the $\mathrm{Mn}$ showed the highest decrease in their concentration after the milling process among the six analyzed elements, i.e. $88 \%$. No other comparative data have 
been found regarding the Mn content in white flour and wholemeal. Based on this study, the daily Mn requirement can be easily covered from $100 \mathrm{~g}$ wholemeal, but not from white flour.

It was reported that Mo is more highly concentrated in the fine and coarse bran fractions than in flour fractions (Stroud et al. 2010). Even so, the data on varieties showed that the milling of wheat grains only slightly reduced the Mo concentration in white flour, but it was not significant. Interestingly, the commercial white flour enriched with germ had higher Mo concentration than wholemeal. Based on this data, the Mo requirement of adults (45 $\mu$ g per day, Dietary Reference Intake 2004) can be satisfied by normal diets in Hungary. Calculating with the average Mo concentrations in the BL55 white flour (245 $\mu \mathrm{g}$ $\mathrm{kg}^{-1}$ ), the requirement of adults could be met by the daily consumption of $190 \mathrm{~g}$ white flour. The average Mo concentration in the white flour of varieties was only $108 \mu \mathrm{g} \mathrm{kg}^{-1}$, due to the possible low soil Mo concentration.

In summary, this study revealed a significant variation in the micronutrient content among wheat flour products available in Hungary. Especially the variation in the Se, Mo and Fe concentrations of the different brand of white flour was remarkable. Commercial flours are mainly mixtures of grains of different varieties originated from different cultivation areas; therefore, by using conventional farming system it is difficult to guarantee the production of flour only from varieties with high nutritional value. However, organic farming is a closed-chain production system, where the production-chain is strictly controlled; therefore it is perfect to use such varieties showing better nutritional values.

The wholemeal has higher $\mathrm{Cu}, \mathrm{Fe}, \mathrm{Mn}$ and $\mathrm{Zn}$ concentration on average than refined flour, but Mo and Se content is not affected significantly by milling. Additionally, the daily Mo, Mn and Fe requirement can be covered by the consumption of $250 \mathrm{~g}$ wholemeal flour in Hungary. Even though the total daily micronutrient requirement is covered not only by wheat-based products, flour with higher $\mathrm{Zn}, \mathrm{Cu}$ and $\mathrm{Se}$ micronutrient is demanded. So, agronomic or genetic biofortification is suggested to increase the mentioned mineral content of wheat. Although, the breeding for high $\mathrm{Zn}, \mathrm{Cu}$ and Se concentration would be difficult, while no or small genotype effect was found in this study. The examined modern cultivars may represent narrow genetical base, where environmental factors exert a greater effect. The genetical biofortification would be realistic, when more diverse material, where genetical variation in micronutrient concentration existing is used. The genetical biofortification could succeed on condition that in the used plant material the genetical variation in micronutrient concentration is significantly greater than in the genotypes evaluated in this study.

\section{Acknowledgements}

This work was supported by the Hungarian Research Fund (OTKA PD72080, principal investigator: A.F. Bálint) and by a Bolyai-Fellowship (2010-2012) for A.F. Bálint. 


\section{References}

Bálint, A.F., Kovács, G., Erdei, L., Sutka, J. 2001. Comparison of the $\mathrm{Cu}, \mathrm{Zn}, \mathrm{Fe}, \mathrm{Ca}$ and $\mathrm{Mg}$ contents of the grains of wild, ancient and cultivated wheat species. Cereal Res. Commun. 29:375-382.

Broadley, M.R., Bowen, H.C., Cotterill, H.L., Hammond, J.P., Meacham, M.C., Mead, A., White, P.J. 2004. Phylogenetic variation in the shoot mineral concentration of angiosperms. J. Exp. Bot. 55:321-336.

Cakmak, I. 2008. Enrichment of cereal grains with zinc: Agronomic or genetic biofortification? Plant and Soil 302:1-17.

Cakmak, I., Torun, A., Millet, E., Feldman, M., Fahima, T., Korol, A., Nevo, E., Braun, H.J., Ozkan, H. 2004. Triticum dicoccoides: An important genetic resource for increasing zinc and iron concentration in modern cultivated wheat. Soil Science and Plant Nutrition 50:1047-1054.

Codus Alimentarius Hungaricus 2007. http://www.gabonaszovetseg.hu/dokumentumok/EK_liszt.pdf (Accessed 06.03.2013).

Cubadda, F., Aureli, F., Raggi, A., Carcea, M. 2009. Effect of milling, pasta making and cooking on minerals in durum wheat. J. Cereal Sci. 49:92-97.

Dietary Reference Intakes (DRIs): Recommended Intakes for Individuals, Food and Nutrition Board, Institute of Medicine, National Academies, 2004. (Retrieved 09.06.2009.)

Erba, D., Hidalgo, A., Bresciani, J., Brandolini, A. 2011. Environmental and genotypic influences on trace element and mineral concentrations in whole meal flour of einkorn (Triticum monococcum L. subsp monococcum). J. Cereal Sci. 54:250-254.

Garvin, D.F., Hareland, G., Gregoire, B.R., Finley, J.W. 2011. Impact of wheat grain selenium content variation on milling and bread baking. Cereal Chem. 88:195-200.

Gomez-Becerra, H.F., Yazici, A., Ozturk, L., Budak, H., Peleg, Z., Morgounov, A., Fahima, T., Saranga, Y., Cakmak, I. 2010. Genetic variation and environmental stability of grain mineral nutrient concentrations in Triticum dicoccoides under five environments. Euphytica 171:39-52.

Graham, R.D., Welch, R.M., Saunders, D.A., Ortiz-Monasterio, I., Bouis, H.E., Bonierbale, M., De Haan, S., Burgos, G., Thiele, G., Liria, R., Meisner, C.A., Beebe, S.E., Potts, M.J., Kadian, M., Hobbs, P.R., Gupta, R.K., Twomlow, S. 2007. Nutritious subsistence food systems. In: Sparks, D.L. (ed.), Advances in Agronomy. Elsevier Academic Press Inc., San Diego, USA. Vol. 92, 74 pp.

Lyons, G., Ortiz-Monasterio, I., Stangoulis, J., Graham, R. 2005a. Selenium concentration in wheat grain: Is there sufficient genotypic variation to use in breeding? Plant and Soil 269:369-380.

Lyons, G.H., Genc, Y., Stangoulis, J.C.R., Palmer, L.T., Graham, R.D. 2005b. Selenium distribution in wheat grain, and the effect of postharvest processing on wheat selenium content. Biological Trace Element Res. 103:155-168.

Mayer, J.E., Pfeiffer, W.H., Beyer, P. 2008. Biofortified crops to alleviate micronutrient malnutrition. Current Opinion in Plant Biol. 11:166-170.

Monasterio, I., Graham, R.D. 2000. Breeding for trace minerals in wheat. Food and Nutrition Bulletin 21:392-396.

Murphy, J., Cashman, K.D. 2001. Selenium content of a range of Irish foods. Food Chem. 74:493-498.

O'Dell, B.L. 1972. Distribution of phytate and nutritionally important elements among the morphological components of cereal grains. J. of Agricultural and Food Chem. 20:718-721.

Oktem, A., Oktem, A.G. 2009. Mineral composition of some turkish durum wheat genotypes. Asian J. of Chem. 21:2733-2738.

Oury, F.X., Leenhardt, F., Remesy, C., Chanliaud, E., Duperrier, B., Balfourier, F., Charmet, G. 2006. Genetic variability and stability of grain magnesium, zinc and iron concentrations in bread wheat. Eur. J. Agron. 25:177-185.

Ozturk, L., Yazici, M.A., Yucel, C., Torun, A., Cekic, C., Bagci, A., Ozkan, H., Braun, H.J., Sayers, Z., Cakmak, I. 2006. Concentration and localization of zinc during seed development and germination in wheat. Physiologia Plantarum 128:144-152.

Sigrist, M., Brusa, L., Campagnoli, D., Beldomenico, H. 2012. Determination of selenium in selected food samples from Argentina and estimation of their contribution to the Se dietary intake. Food Chem. 134:1932-1937.

Spadoni, M., Voltaggio, M., Carcea, M., Coni, E., Raggi, A., Cubadda, F. 2007. Bioaccessible selenium in Italian agricultural soils: Comparison of the biogeochemical approach with a regression model based on geochemical and pedoclimatic variables. Sci. of the Total Environ. 376:160-177.

Cereal Research Communications 
SPSS Statistics for Windows, Version 17.0. 2008. SPSS Inc., Chicago, USA.

Stroud, J.L., Zhao, F.J., Buchner, P., Shinmachi, F., Mcgrath, S.P., Abecassis, J., Hawkesford, M.J., Shewry, P.R. 2010. Impacts of sulphur nutrition on selenium and molybdenum concentrations in wheat grain. J. Cereal Sci. 52:111-113.

Ward, J.L., Poutanen, K., Gebruers, K., Piironen, V., Lampi, A.M., Nystrom, L., Andersson, A.A.M., Aman, P., Boros, D., Rakszegi, M., Bedo, Z., Shewry, P.R. 2008. The HEALTHGRAIN cereal diversity screen: Concept, results, and prospects. J. of Agric. and Food Chem. 56:9699-9709.

Zhao, F.J., Su, Y.H., Dunham, S.J., Rakszegi, M., Bedo, Z., Mcgrath, S.P., Shewry, P.R. 2009. Variation in mineral micronutrient concentrations in grain of wheat lines of diverse origin. J. Cereal Sci. 49:290-295. 